\title{
Design Style of Product in Spectacle Context
}

\author{
Yuzhou Wu \\ Huaiyin Institute of Technology \\ Huaian, Jiangsu, China 223001
}

\author{
Yuelei Wang \\ Huaiyin Institute of Technology \\ Huaian, Jiangsu, China 223001
}

\begin{abstract}
In spectacle society, image becomes the main cause of the world, and the visual style is superior to everything. In spectacle society, the design style of product is mainly manifested in the following aspects: at the level of ID, the appearance is beautified to satisfy the sensual desire of the vision; on the level of ego, the form is divided to meet the status symbol. In the end, this paper makes reflection of the temptation of the design style, and from the level of super-ego, points out the design of "good things" to meet the needs in ethical and moral level.
\end{abstract}

Keywords-image; design; style; aesthetic; distinction

\section{INTRODUCTION}

It is necessary to pay attention to the corresponding social state in order to explore the suitable design expression. China's metropolis is becoming (or has evolved into) what Guy Debord called "all life in an omnipresent society under modern production conditions presented as an infinite accumulation of spectacle. Everything is transformed into representation"[1] (Spectacle[2]) Social, living places, workplaces, leisure venues are all filled with the designed, decorated wonderful images, elegant living conditions, standard beautiful women, Lively and attractive pictures, colorful and dazzling.

In spectacle society, the "display" of the image replaces the "possession" of the object and becomes the label of individual identity. The homogeneity of man and object changes into the homogeneity of human and image. The appearance of the object and the nature of the appearance all changed. In this case, the image will occupy a leading position, no longer need to be interpreted its legitimacy, itself is enough to explain all; the image creation becomes the design center, "form expression is superior to all", improve the "Visual, personality and similarity" of the product form becomes the key to achieve the "Representational property"[1] of the product. In the field of design, style can be used for "appearance", with meaning, it can cause association, which itself means a particular kind of content selection. In order to make the product become a desirable ornamental object, the style characteristics of the product are deliberately exaggerated during the design process, that is, the product image is stylized. In the process of stylization, the formal system symbolizes the visual desire, the identity appeal and the moral tendency of the viewer, and expresses as the exaggeration of visual aesthetics, distinguishing feature and ethical choice in the style expression.

\section{Manufacturing Beauty: To MeEt the Visual DESIRE}

When the product is all transformed into the image, the visual is raised to the lofty position. The product experience in the past is simplified into visual watching, product appearance becomes the only thing of the product, regardless what "intent" does the initial product have, ultimately will transformed into the "transmission carrier" of image[2]. The focus of the design shift to the pursuit of beauty, the complexity internal must be hidden in a visually appealing appearance, function, rational, ethical and moral judgments after the consumer's aesthetic.

Aesthetic myth tantalizing the consumers' desire, novel and moving, sophisticate designed products make consumers' sensual pleasure and make them sink in the "meet desire - stir up desire" cycle. Design is for temptation, it no longer has a clear precept. Design can be clear, rational, classic, fine, it can also be full of changeable, emotional, novel, harassment, or even weird, mixed, rude, extravagant, nothing is impossible. Diversified social stratification, minority of the market layout, and personalized consumer demand make us know: every style has been sought after, the only loser is "invariable". At all times and in all countries, the diabolic tricks and wicked craft, not limited to one type, free and changeable, eye-catching should be the commercial design performance under current context, and also a reflection of contemporary people's life demand.

In the capital-dominated consumption economy, after the aesthetic appearance form, capital, designers, sellers also create a seductive "atmosphere "through the series of ways to present the abstract psychology perception with a systematic, holistic approach in front of the viewer. The "viewer" is set as a "functional person": through the "never in contact with each other" interpersonal communication, to make people concerned about the "atmosphere" concept, create the atmosphere through the image and make a full display of its owner, people "will not view this product from the special purpose, but view the whole set product from its full sense"[3]. In this way, object becomes the background of people (not only the behavior background, but also the cultural background).

The design speech method associated with this is from the lexical language (an image corresponding to a product) transit into system language (the value of image lies in the difference with other images). The systematic linguistic approach inevitably requires structural and hierarchical processing. The forms, materials, colors, and textures of the image all become 
functional and mobile elements, which are separated from their original nature. Take one-piece anodized aluminum which used on iphone6 plus for example, it is due to today's high-tech vision and the pursuit of light and thin. In fact, there are many selections for the phone shell material (PC, ABS, ordinary engineering plastics, glass), any material can complete the specific functions, however iPhone6Plus choose anodized aluminum is based on (1). distinction from the material of previous product iPhone5 (glass), (2). round-shaped natural shape connection needs, (3). the concept output of scientific and technological innovation. Use the aerial material on iphone6 plus metaphor advanced, advanced, high-grade, precise technology, which transmit the innovation, breakthrough, high-quality, high-tech corporate culture. Objectively speaking, any material does not have life, character or meaning, metal material is not higher than the plastic, wood is not better than glass, alumina does not necessarily represent the above meaning, these so-called properties (meaning)only "valid in cultural consciousness concept"[6].This property may also change from time to time, here material is abstracted into a property (different material implies a certain property), and as such, the various materials "can thus constitute a system of close coherence. The abstracting process makes the infinite combination between them possible." The material selection becomes a culture selection (not just the selection of the natural attributes of materials), which subject to the manipulation of the atmosphere, subject to the" symbolic cultural system"[7].

Nowadays, the meaning of design elements (form, material, color, texture, etc.) transmit more to the related cultural system, it is to cultivate their own cultural values. Showroom, display window, shopping mall, advertisement, brand and trademark play a major role here, "to impose a consistent collective concept, like a chain, an inseparable whole, they are no longer a bunch of simple products but rather a bunch of meanings, because they hint at each other more sophisticated upscale products and give consumers a more complex set of motivations."[6] Product image through juxtaposition with other (product, character, and environment) images to obtain unrelated properties such as romance, luxury, wealth and beauty. Product image considered not only as the background of certain concept but also the concept representation. Product images formed a psychological connection between each other, "logically from one commodity to another commodity", product $\mathrm{A}$ implies lifestyle $\mathrm{A}$, associated with the product $\mathrm{B}$, product $\mathrm{C}$, product $\mathrm{A} \backslash \mathrm{B} \backslash \mathrm{C}$ linked together through lifestyle A. The most successful psychological hypnotism in a spectacle society is that when you choose product A, you will have lifestyle A, and you will unconsciously instigated to take possession of product $\mathrm{B}$ and product $\mathrm{C}$, and even more products in the same collective view. The designer is the executive of this hypnotism, who is responsible for the performance of the "collective concept" in the product image (by selecting the appropriate elements), the designer is responsible to "open the indicative road, inducing people stuck into the shopping impulse in commodity network. And make induction and improve based on their own logic until receive the maximum investment".[8]

\section{SOCIAL Distinction SyMBOLS: Highlight THE NEEDS OF SOCIAL IDENTITY}

People and image style tend to be homogeneity, "different styles are more or less automatically express the social functions in different social hierarchical levels". [8]People define" the identity of social members" through the objects themselves and their sums [9], the image of objects and their atmosphere structure formed the symbol of people's status. McLuhan divided people into low, medium, high consumers based on the quality of consumption and using products. Under the image aggregation, the consumption level shows more obvious, consumer groups "strive to the upper level", show off their own value through high-quality products in order for the recognition of others. It is worth pointing out that the quality of the product (here) is not limited to the original usefulness, durability, usability, safety and other physical qualities, it tend to the cultural, social communication and symbolic meaning sublimation, the quality is depends on if the product image can be characterized by wealth, elegance, authority and noble.

Ancient emperors "use the most precious raw materials, and through the most exquisite painting and carving techniques to polish these materials and give its elegant appearance", "consciously exaggerated show off the material luxury, enhanced the social prestige and political rights related to art from visual sense". [10] The current elite classes still build their own luxury code with the same logic. Advanced, valuable materials (whether from foreign countries or from the latest technological achievements), from the hands of design experts, using the latest production technology (or purely handicraft production), the excellent quality and the scarce quantity formed a natural separation between those who using massproduced products. The users of high quality products "deliberately display" or show off their "Status symbol", make it becomes the counterpart of social stratification. [11]This kind of show off does not need hard rules (different with the regulations in emperor times), they can obtain a great degree of recognition only through the use of products which the mass cannot have and then through the image communication and education.

High-level consumers intentionally show the "status symbol", while the low-level (medium, low-level) consumers through certain channels to imitate high-level products in some aspects in order to cover up their own symbols. When the imitation becomes real, the "status symbol" of the two sides will be confused, and the high-level consumers will look for a new symbol. From this logic point of view, the most important feature of luxury products is scarcity (scarcity established the high-level status of object in symbolic structure of object system). This scarcity can be material, can be art, of course can also be time, that is, fashion. High-end consumers create fashion, the end consumers follow, imitate the fashion, and low-end consumers never make contact with fashion.

Although fashion "is always appropriate, no matter how it looks or how it is expressed; as long as it is fashion, it can keep individuals free from the unpleasant experience when they were noticed "[12]. It can coordinate the balance between new and old, singular and ordinary, it can soothe consumers' anxiety, but its most important role is not this, but it can make 
distinction from low-level group by its timeliness. Fashion does not dance with scarcity like the luxury, it is more about the taste. Bourdieu in "distinction" believed that the distribution and mode of taste should be "treated together with the class, occupation, wealth, education and other social factors", and make taste and people completely homogeneous, "dress the same with others means they have the same identity"[13], choose a taste means different with other ways and styles. Obviously, when a certain fashion style is established and recognized, it means that the styles and lifestyles besides this fashion are excluded (non-tasteful). In fact, with the increase of image diversity, the taste of different products, designs, styles do not have single standard, and when designers try to establish fashion and taste standard, the consumers can choose not to recognize. However, designers still are the fashion advocates, communicators, and manufacturers. The fashion shows released by Paris fashion designers every year almost established the annual fashion trends.

Fashion detaches function and constructs differences, and uses psychological suggestion means to prompt consumers to get rid of the old and welcome the new. However, the fashion objects provided by designers will absolutely not be fundamental new image, but based on the relationship model between "familiarity - novelty" and pleasure (sensual pleasure increased with novelty, when the familiarity reaches a certain intensity, the sensual pleasure declining from the peak), to provide a familiar and unfamiliar image. According to Barthes's popular symbol analysis, the design matrix established by "object", "support object" and "variable" together, "minutiae can change the appearance of the whole universal" [16]. The popularity normally changed through two ways:(1). "Maintain the same style, but change or add other variable terms", (2). "Let some features disappear, and mark the new features"[17] More bluntly speaking, the so-called fashion change is the detail update of the prototype. Through this update and adjustment, after publicity advertising, exaggerated the excellent after the update, implied the lack of other products, induce consumers abandoned other products.

\section{SELF-EXAMINATION: THE TEMPTATION BEYOND OBJECTS?}

Spectacle gathering, rich materials, a lot of beautified products, fantastic atmosphere, elegant life, taste image surround people, the image stylization brought pleasure to people and it covered the consumer behind it smoothly. There is no doubt that the spectacle society in which we live is a comprehensive consumer society, in which product is image, image is capital, product, image and capital are combined in consumption. In the image consumption context, the product (image) is completely descended to the temptation product (image). When desire exceeds demand, the difference (relationship) exceeds function (itself) to become a major factor in the product value, style exceeds content and becomes the design focus: product image becomes the tool to create dream, attract eyes and instigate desire, it removed itself from functional value (aesthetics, pleasure), and transfer into the status symbol and wealth symbol. Form is no longer just a change of straight and dense in space and surface, but is a complete symbol filled with people and the whole world. The associated designs evolved into: the satisfaction and awakening of consumer desires, the creation and emphasis of differences between consumer goods, and the supply of special lifestyles.

In fact, the aesthetic object, atmosphere object, scarcity object and distinction object are nothing but some kind of temptation appearance, the ultimate goal is not to bring real satisfaction, but to create business opportunities for the capital side and earn economic profit. Commercial and manifested conspiracy will inevitably lead to emphasis on style, the pursuit of diversity, the status attention, making the rapid replacement of product images, product life is artificially shortened, resulting in a huge waste, threatening the long-term survival of mankind.

Based on the principle of economy, product is descended to the temptation object, based on the principle of morality, it is necessary to explore how the product becomes good object. Products exist for their effectiveness, the objects for humans, the ultimate goal is to protect human itself, weapons used to protect themselves from other species' attack, clothes used to protect themselves from cold and heat, tools used to protect themselves from material scarcity, constructions used to protect themselves from natural environment. The ultimate goal of design is to protect not threat, but because of business, economic alienation, the usefulness of product gives place to the beauty of image, creative activities gradually evolved into deceptive activities, designers in which can not shirk responsibility (If the designers still think they are important).

\section{CONCLUSION}

Design issued a series of statements, provided a series of bills. In the image overflow, sensual proliferation context try to find a law to guide the designers' practice and also lead people's lives, but it can not: (1). Product stylization meet the human desire while provoking greater object desires, which caused greater emptiness; (2). This spiral type growth is subject to limited resources, so it can not last longer; (3). Even more frightening is that we can almost use all perspectives to examine, it can be ecological, structural, historical, geographical, human, commercial, political, but we can not choose which way is more convincing. Design is the blend of current and future, the future continues its inversion in the image regardless of the actual situation, or return the true to reality, the designer must make a responsible choice. If the designers want to create good object, they must jump out of the cage of image logic and consumption logic, reduce product timeliness with overall positive care, change the product's living environment, expand the existence meaning of artifacts, change people's collective ideas, to help mankind separate from the mass production, infinite expansion amount, waste around body material world, and enter into a new world which set up because of needs, make the best use of everything, exhausted its material, flexible, high-quality, respect for the ecological environment. 


\section{REFERENCES}

[1] Quoted from The turning of Visual Culture [M].Zhou Xian Nanjing: Nanjing University Press, 2008,1: 120.

[2] Spectacle can be translated into Chinese as: landscape, image, scene, the text use"landscape" to differentiate with "image".

[3] [US]Art, Architecture [M]. Hal Foster. Translate by Gao Weihua. Jinan: Shandong Pictorial Publishing House, 2013, 07: 10.

[4] Visual art meaning [M].E. Panofsky, translate by $\mathrm{Fu}$ Zhiqiang. Shenyang: Liaoning People's Publishing House, 1987,8: 14.

[5] Consumer society [M]. [Fr]Jean-Baudrillard, translate by Liu Chengfu.Nanjing: Nanjing University Press, 2014, 10: 2-3.

[6] Le Systeme Des Objets [M]. [Fr]Jean-Baudrillard, translate by Lin Zhiming.Shanghai: Shanghai People's Publishing House, 2001: 41.

[7] Same as above: 42 .

[8] Consumer society [M]. [Fr]Jean-Baudrillard, translate by Liu Chengfu Quan Zhigang.Nanjing: Nanjing University Press, 2008,10: 3.

[9] Same as above.

[10] Design History and History of Design [M]. [En]John Walker,Atterfield; Translate by Zhou Dandan, Yi Fei.Nanjing: Jiangsu Fine Arts Publishing House, 2011, 4: 113.

[11] Criticism of Symbolic political economy [M]. [Fr]Jean-Baudrillard, translate by Xia Ying.Nanjing: Nanjing University Press, 2015,1: 13.

[12] Modern Design History (second edition) [M]. [US]David Raizman, [Australia] Yolanda Am Wang,translate by Li Chang. China Renmin University Press , 2013, 1, 1: 4.

[13] Extended Symbols and Design Consumption Sociology[J] . Li Yanzu.Journal of Nanjing Institute of Arts, 2007/4, 8-11.

[14] The turning of Visual Culture [M].Zhou Xian. Beijing: Peking University Press, 2008,1 P201.

[15] Design History and History of Design [M]. [En]John Walker,Atterfield; Translate by Zhou Dandan, Yi Fei.Nanjing: Jiangsu Fine Arts Publishing House, 2011, 4:19.

[16] Popular system: semiotics and clothing code,Roland Barthes,translated by Ao Jun. Shanghai: Shanghai People's Publishing House, 2000,5: 73.

[17] Same as above: 211-212. 